\title{
To Enhance Light Extraction for Organic Light-Emitting Diodes by Body Modification of Substrate
}

\author{
Jun Wang, Chong Wang, and Yadong Jiang \\ State Key Lab of Electronic Thin Films and Integrated Devices, School of Optoelectronic Information, \\ University of Electronic Science and Technology of China, Chengdu 610054, China
}

Correspondence should be addressed to Jun Wang; uestc_wj@yahoo.com

Received 23 September 2013; Revised 30 November 2013; Accepted 2 December 2013

Academic Editor: Jun-Ho Yum

Copyright (C) 2013 Jun Wang et al. This is an open access article distributed under the Creative Commons Attribution License, which permits unrestricted use, distribution, and reproduction in any medium, provided the original work is properly cited.

A facile approach of body modification on substrate is introduced to enhance the light extraction for organic devices. The lateral metal reflective film (LMRF) was coated on side of substrate and microlens array (MLA) was fabricated on forward surface of substrate. The two methods of improving light output are simulated and optimized to form body modification. The metal thin film was evaporated on the side of reversal trapezoid shape substrate to form LMRF layer and the MLA with semicircle shape was fabricated on the substrate using normal photolithography process. The external quantum efficiency of fabricated organic device with body modification is $\sim 1.8$ times higher than the device with normal substrate.

\section{Introduction}

Organic light-emitting diodes (OLEDs) have shown tremendous potential in display and solid state lighting (SSL) applications because of their low power consumption, wide viewing angle, excellent color gamut, and fast response time [1-3]. Although an internal quantum efficiency of nearly $100 \%$ has been achieved $[4,5]$, the problem of low light extraction efficiency remains unresolved especially for illumination application [6, 7]. In conventional OLEDs, the refractive index mismatch at the ITO/glass and glass/air interfaces is large enough to induce the total internal reflection of a considerable portion of light coming from the emitting layer. Typically, the fraction of generated lights that is output into the forward viewing space for an OLED fabricated on planar glass is as low as $20 \%[8,9]$.

To recover these waveguide modes, various techniques had been studied with the aim of improving the light output for OLEDs, including low-index grids $[10,11]$, periodic corrugated structure [12], Bragg mirrors [13], buckling patterns [14], photonic crystals [15], antireflection coatings [16], and monolayer of $\mathrm{SiO}_{2}$ microparticles [17]. Those methods focused on changing the contact surface of glass substrate with organic device and mere modification of the external surface of the glass substrate of the OLED to minimize the total internal reflection.

The effectiveness of surface structures (different geometries and materials of microlens) for the light extraction enhancement has been explored by different authors. The microlens array (MLA) using prepolymer NOA65 material was fabricated on the substrate by microcontact printing of hydrophobic self-assembled monolayers, and the light outcoupling efficiency was improved by $24.5 \%$ without any apparent color change [18]. Spherical microlenses patterns using photoresist material were designed on the backside of OLEDs substrate by conventional etching method to minimize the total internal reflection loss at substrate/air interface, and an enhancement of 1.65 could be obtained with high refractive index glass as substrate [19]. Flexible MLA using a mixture of polydimethylsiloxane prepolymer by breath figure method was poured on organic substrate surface and a $34 \%$ of external quantum efficiency enhancement for OLEDs [20]. An irregular hemispherical microlens system made of flat polyethylene terephthalate film with microcavity was used for OLEDs and the external out-coupling factor of the device increases by a factor of $\sim 1.8$ with wide viewing angles [21]. Zinc oxide pillar arrays were printed on the surface of glass substrate by pattern replication method in 


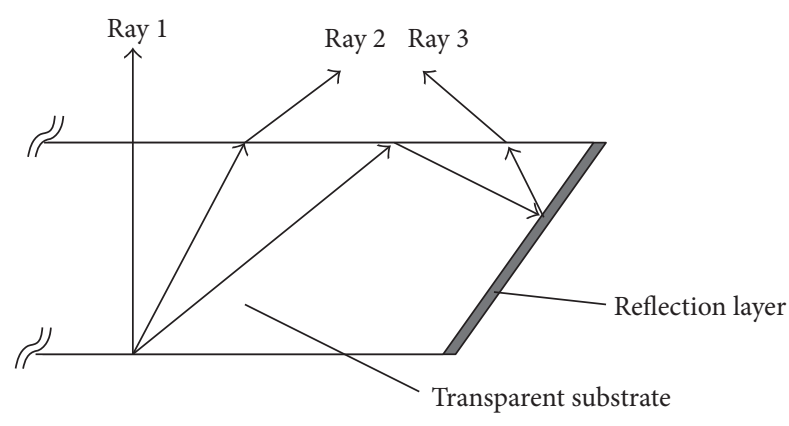

(a)

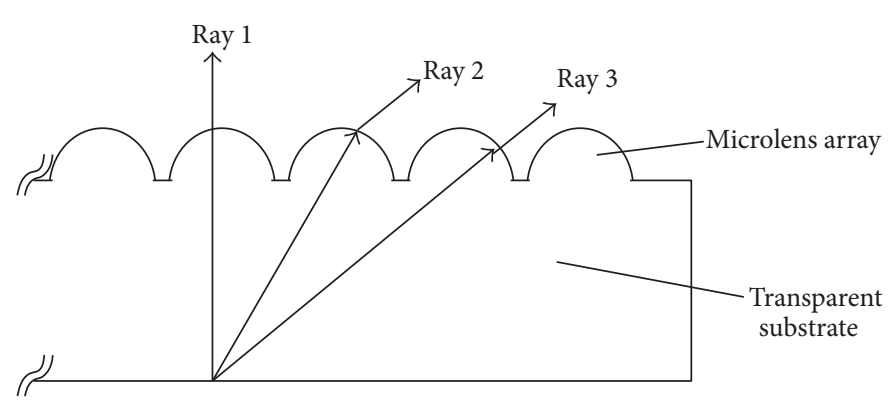

(b)

FIGURE 1: Schematic diagram of light extraction enhancement with LMRF (a) and MLA (b) modification on transparent substrate.

nonwetting templates technique, the devices exhibited the peak emission intensity at an emission angle of $40^{\circ}$, and a $75.0 \%$ enhancement in total light output could be obtained [22]. Using MLA structure on the external surface of substrate could effectively weaken the waveguide phenomenon in substrate and enhance the light output from external surface of substrate. But it could not block light exiting from the side of substrate thoroughly.

In this paper, a novel method of body modification on glass substrate is demonstrated using lateral metal reflective film (LMRF) coated on side of substrate and MLA covering on forward surface of substrate to promote light extraction from organic device. The LMRF on the side of reversal trapezoid shape substrate could forbid light escaping with waveguide mode and reflect those lights to substrate again to form forward light emission. The MLA on the substrate surface enhances the light output from front surface of substrate. Both LMRF and MLA could be easily fabricated on the substrate and compose the body modification for organic devices. The body modification including forward surface and side section of substrate could effectively improve light extraction and light intensity uniformity for OLEDs, especially for SSL application.

\section{Models of Substrate Modification}

Figure 1 presents the schematic diagram of light extraction enhancement with LMRF and MLA modification on transparent substrate. In Figure 1(a), the edge of substrate was cut down with certain angle, polished, and covered with metal reflection layer. Light rays 1 and 2 can escape the substrate to front air, but ray 3 would be reflected to glass and exit from the side of substrate because of the mismatch of glass-air refractive index and large incident angle (higher than critical angle). After setting LMRF at the side of substrate, ray 3 would be reflected to substrate and approach the interface of substrate-air with a different incident angle which is smaller than critical angle. With MLA modification on the glassair interface, the light ray with large incident angle (ray 3) could also be extracted out because the surface of substrate is changed by the lens array as shown in Figure 1(b). Therefore, more lights are extracted out due to the reflection of edge metal layer and morphology changing by microlens array on the substrate.

The device model of light extraction with different modified substrate could be simulated and optimized with ray trace method. In order to identify the influence of LMRF with different cutting angle and MLA with different contract angle to the light output efficiency, three-dimensional models of organic devices with two modification structures are designed, which are briefly demonstrated in Figure 2. The structure of organic device is glass substrate $(50 * 50 *$ $5 \mathrm{~mm}) /$ ITO $(30 * 30 * 0.0001 \mathrm{~mm}) /$ multiorganic layers $(30 *$ $30 * 0.00012 \mathrm{~mm}) /$ aluminum cathode $(30 * 30 * 0.0001 \mathrm{~mm})$. The four sides of substrate are cut down with different cutting angle and covered with $100 \mathrm{~nm}$ LMRF. For the MLA modification in Figure 2(b), the microlens is residual spherical crown of a sphere which is separated to two parts with different contact angle. The microlenses cover on the whole forward surface of glass with perpendicular arrangement, and the dimension choice of the microlens depends on the fabrication process of the microlens array and former reports about MLA. Both LMRF and MLA structures would be used to form the substrate body modification for OLEDs. For simplicity, the metal layer is regarded as ideal reflecting layer, and the absorption parameter of organic material is set to zero. Refractive indexes of organic material, ITO anode, and glass substrate are $1.8,1.8$, and 1.5 , respectively, referencing from former reports [23-25].

\section{Results and Discussion}

The simulation illuminance maps of substrate forward surface of OLEDs are shown in Figure 3, in which (a) is the OLEDs with normal substrate, (b) with LMRF structure substrate, (c) with MLA structure substrate, and (d) with body modification substrate. The simulation process is carried out using 100 thousands rays with a typical green light wavelength of $540 \mathrm{~nm}$. From the simulation result in Figure 3(a), there is very low light emission near the margin of substrate and the total flux ratio is $21.5 \%$ for the normal glass substrate, which is near other's reports $[26,27]$. After setting LMRF at four sides of substrate, the light output intensity at the margin of substrate is obviously enhanced and there is distinct light extraction area reflected from the four LMRF layers. The total 


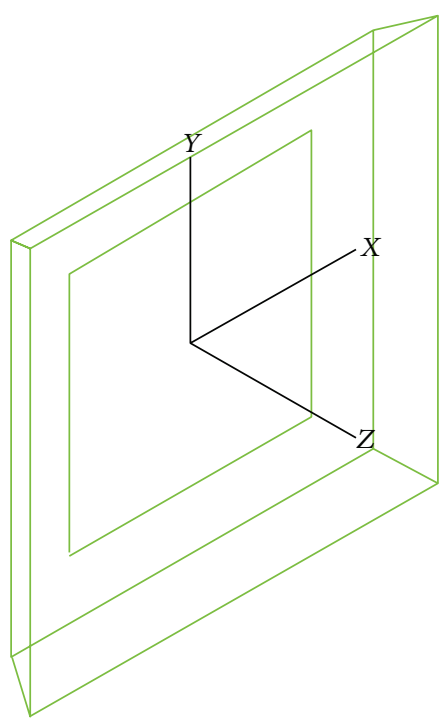

(a)

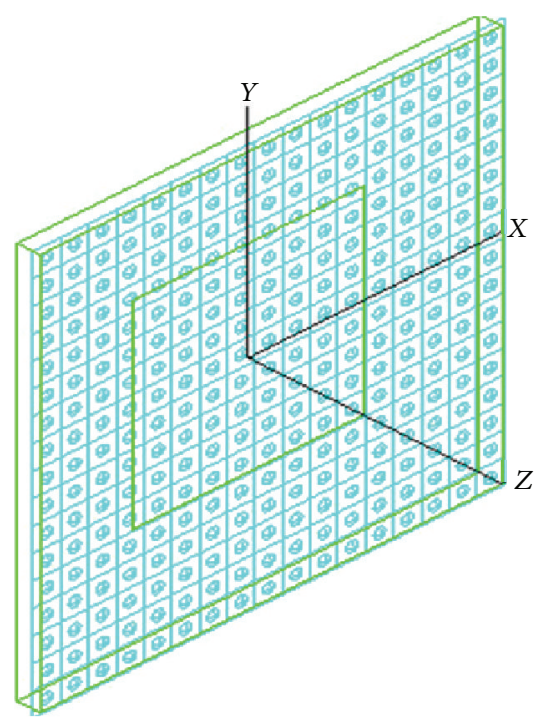

(b)

FIGURE 2: 3D models of multilayer OLEDs with different substrate modification, (a) using the substrate with LMRF structure and (b) using the substrate with MLA structure. The dark square line in the center of substrate is the multilayer device and both electrodes.

flux ratio of OLEDs with a $40^{\circ}$ cutting angle substrate achieves $43.2 \%$, as indicated from Figure 3(b). From Figure 3(c), it can be seen that the light output intensity is promoted in the center of glass substrate and weak enhancement around the margin of the substrate. $38.7 \%$ light extraction ratio could be obtained from the organic device with microlens array structure on the surface of glass substrate (the contact angle of microlens and substrate is $90^{\circ}$ ). The simulation result of organic device with body modified substrate is shown in Figure 3(d). Light output intensity is observably improved not only in the center but also at the four margins of glass substrate. The light output ratio is $46.6 \%$ for the body modified substrate device, which is 2.15 times of the organic device with normal substrate shown in Figure 3(a). At the same time, the light output uniformity of device with body modification is improved compared with the single substrate modification method.

The cutting angle of substrate side and surface morphology of microlens would affect the light extraction from substrate according to the simulation results. The light output ratios of organic devices with different cutting angle of substrate side and different contact angle of MLA/substrate are indicated in Figure 4. The demonstration diagrams of the cutting angle and contact angle are also inserted in Figure 4 for describing the modification clearly. We attempt to descript the mathematical expression between the light output ratio and cutting angle, but the emission light from OLEDs with different incident angles reaches the LMRF layer and is reflected to different surface of substrate. The emission light which exits from substrate changes with the cutting angle, which is uneasy to express with equations. The total light output ratio at different cutting angles is given in Figure 4 and the maximum output ratio is $43.2 \%$ (simulation results) for OLEDs when the substrate with a $40^{\circ}$ cutting angle. The light output ratio decreases quickly at large cutting angle $\left(>70^{\circ}\right)$ and reaches $21.5 \%$ at $90^{\circ}$ cutting angle (which means to be a normal substrate).

The radius $(r)$ and height $(h)$ of microlens (spherical crown profile) could be defined as

$$
\begin{gathered}
r=R \sin \alpha, \\
h=R-R \cos \alpha,
\end{gathered}
$$

in which $R$ is the radius of sphere and $\alpha$ is the contact angle of microlens with the substrate. With the value of $\alpha$ and $R$, the model of microlens could be built and light output ratio of organic devices with different microlens array is shown in Figure 4 . The light output ratio increases from $31.2 \%$ to $38.7 \%$ when the contact angle changes from $30^{\circ}$ to $90^{\circ}$ and indicates a linear relationship with the contact angle. The influence on light output efficiency of MLA/substrate contact angle is similar with the results of the microlens fill factor on substrate [28].

The LMRF layer on the side of substrate can be easily fabricated and the brief process is presented in Figure 5(a). The four sides of glass substrate were cut off and showed reversal trapeziform profile. Then the side surface was polished and etched to form a glossy flat. After that, $100 \mathrm{~nm}$ aluminum metal thin film was evaporated on the four side surfaces of substrate to form metal reflection layer. Image of the substrate with LMRF is shown in (4) of Figure 5(a). Figure 5(b) illustrated the concise preparing process of MLA covering at forward surface of substrate briefly. The transparent substrate (1) with ITO film was spun coating a thick layer of photoresist (2), and then the photoresist pattern (3) was formed on the substrate using normal photolithography process and photomask. To achieve hemispherical type lens array (4), the substrate was post-bake in oven at $140^{\circ} \mathrm{C}$ temperature for 30 minutes. Scanning electron microscope image of the microlens array was described in (5) of Figure 5(b), which 


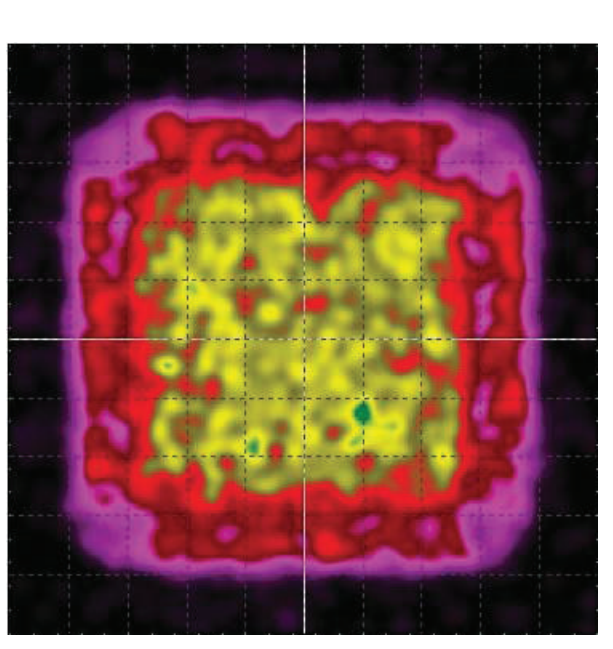

(a)

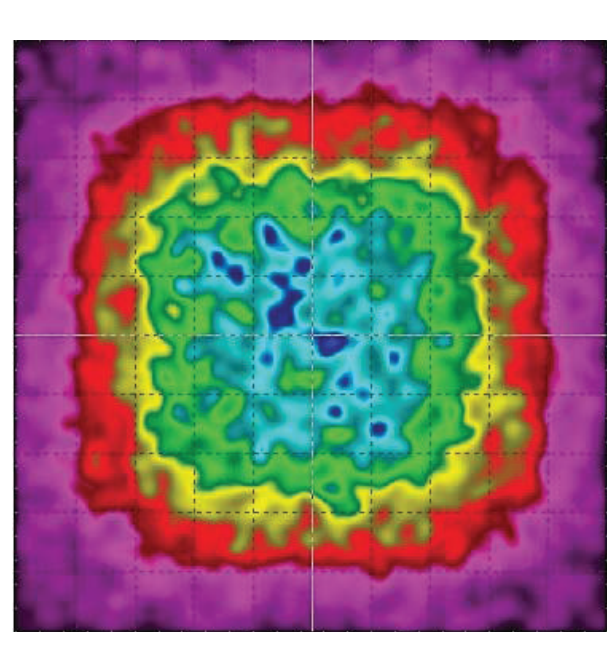

(c)
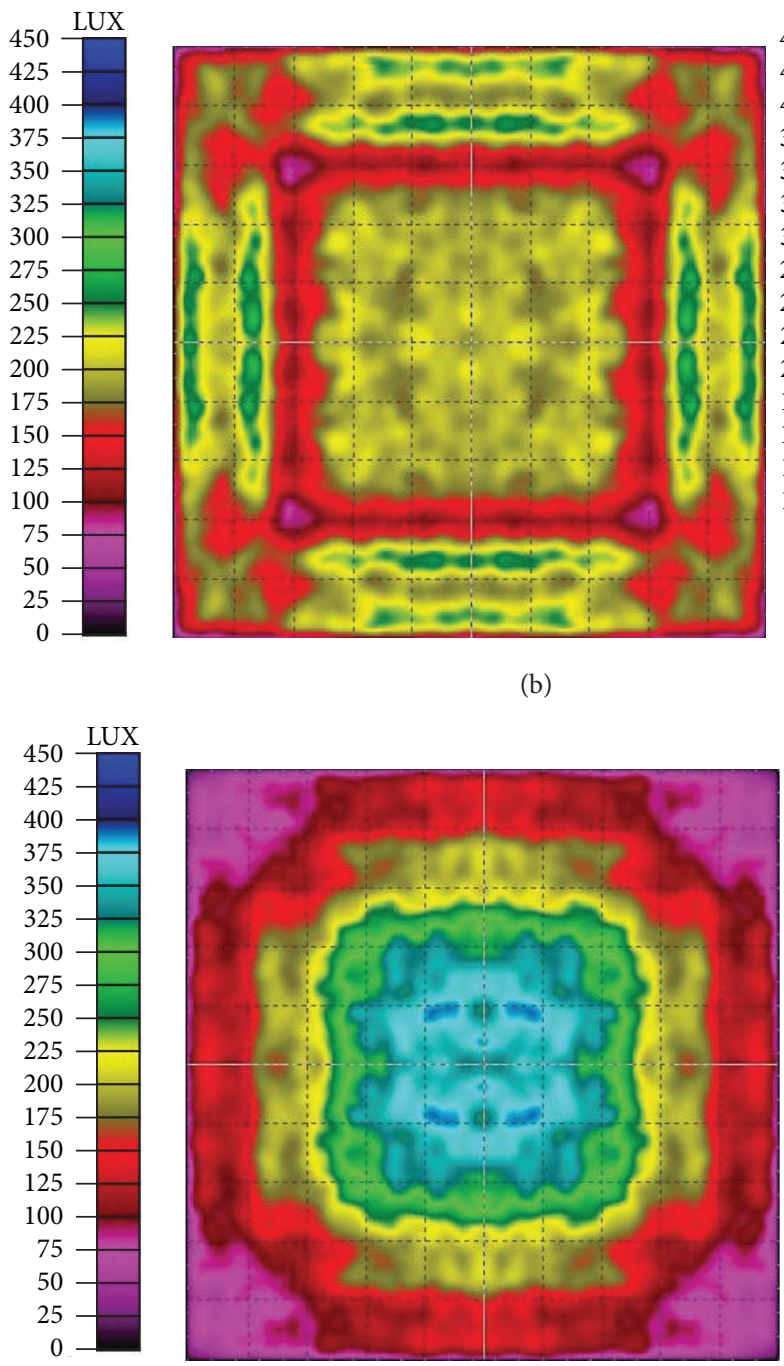

(d)
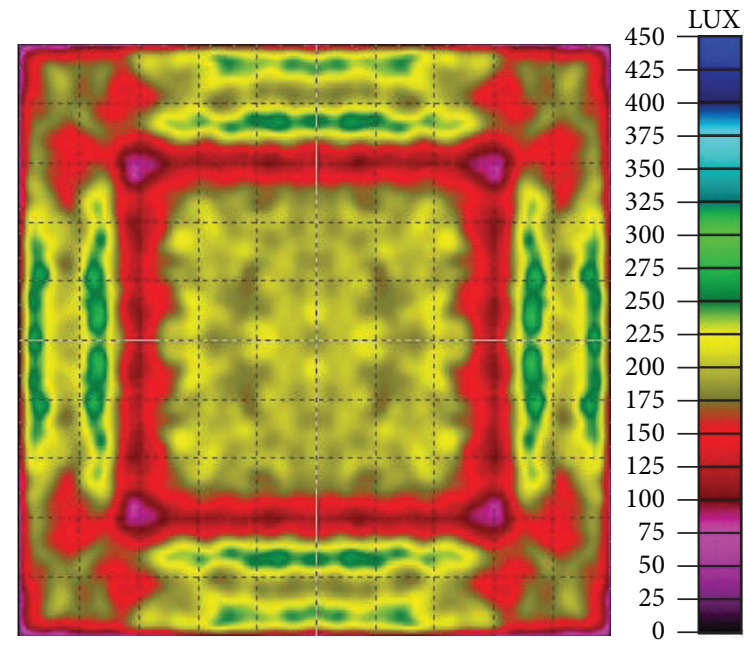

(b)

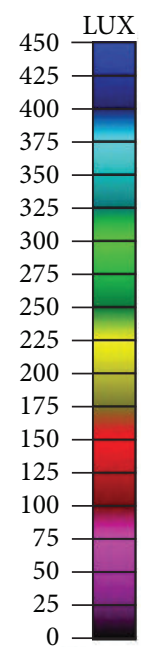

FIGURE 3: The simulation illuminance maps at substrate output surface of OLEDs with different substrate, (a) with normal substrate, (b) with LMRF structure substrate, (c) with MLA structure substrate, and (d) with body modification substrate.

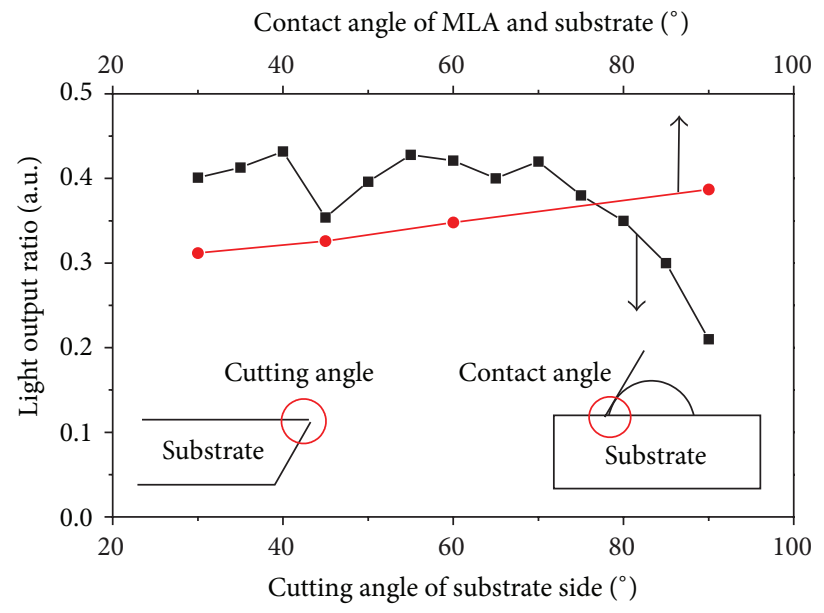

FIGURE 4: Light output ratio of organic devices with different cutting angle of substrate side and different contact angle of MLA/substrate from ray trace simulation; the insets are the demonstration diagram of cutting angle and contact angle. 
(1)

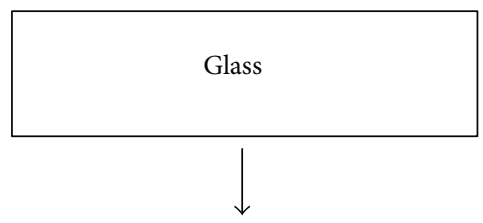

(2)

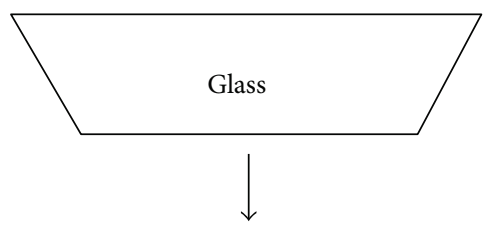

(3)

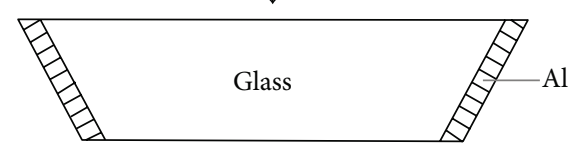

(4)

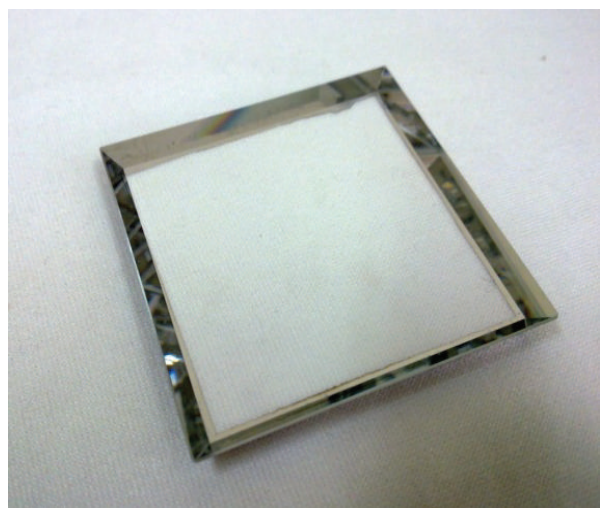

(a)
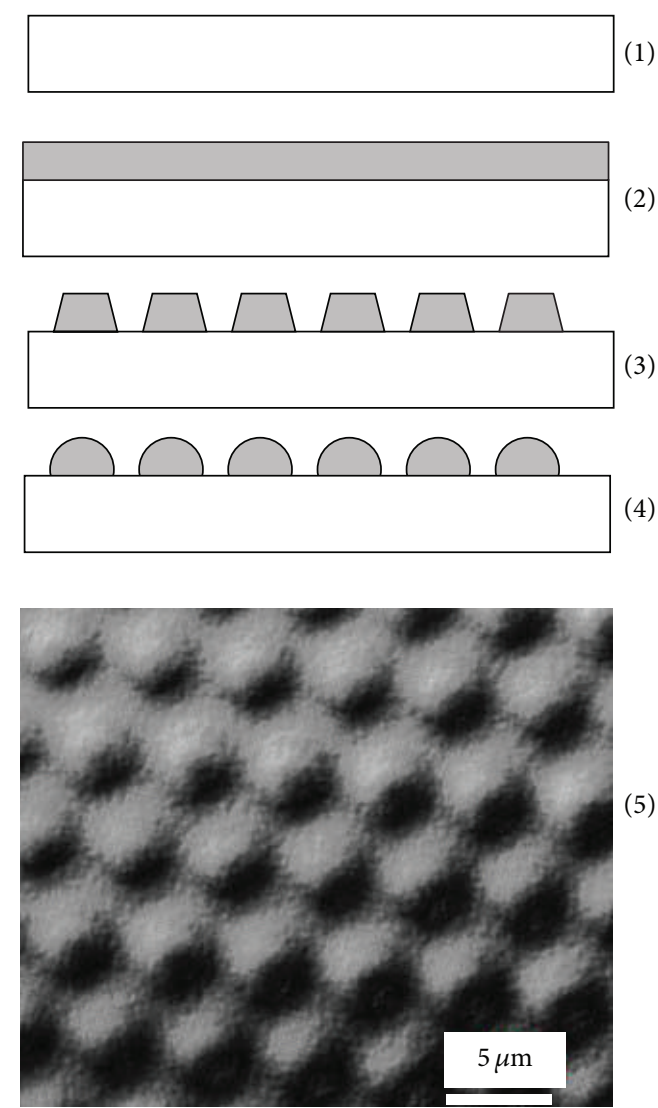

(b)

FiguRE 5: Brief fabrication process of LMRF (a) and MLA (b) structure on substrate. In (a), (1) is the glass substrate, (2) is cutting four lateral angles of substrate, (3) is coating metal reflective layer, and (4) is the image of substrate with LMRF layer. In (b), (1) is the glass substrate, (2) is spun coating microlens material, (3) is patterned by photolithography process, (4) is pattern after high temperature baking, and (5) is the SEM image of microlens array.

indicates that the microlens array with semicircle shape has been formed. The height and diameter of microlens are $2 \mu \mathrm{m}$ and $5 \mu \mathrm{m}$, respectively. With the dimension, the contact angle of microlens/substrate is calculated to be $\sim 78^{\circ}$. The gap between the microlenses is $\sim 0.5 \mu \mathrm{m}$. The size of the microlens array is much smaller than the microlens fabricated with print or self-assembled method [29, 30].

The light output improvement of substrate with LMRF and MLA structure can be characterized by a white LED dot source and those images are shown in Figure 6. Figure 6(a) shows the picture of LED through normal glass with $5 \mathrm{~mm}$ thickness and Figure 6(b) indicates the image of using same source crossing through the substrate with LMRF structure. There is obvious light halation around the dot source and four reflection dots at the substrate side, which means more lights extracting from the forward surface of substrate than the device with normal substrate. The red spots in (b) are indicative of a weak distributed feedback resonance in the substrate caused by the reflective sides. Comparing light output images of LED through the substrate (normal glass with $1 \mathrm{~mm}$ thickness) with (Figure $6(\mathrm{~d})$ ) and without (Figure 6(c)) microlens array, the emission area and light intensity have been improved in Figure 6(d), which is similar to the former simulation results shown in Figure 3.

OLEDs were fabricated on different substrates (normal substrate, substrate with MLA, substrate with LMRF, and substrate with body modification) with device structure ITO/NPB (40 nm)/CBP: (tpbi) $)_{2} \operatorname{Ir}(\mathrm{acac})(2 \mathrm{wt} \%, 30 \mathrm{~nm}) / \mathrm{BCP}$ $(10 \mathrm{~nm}) / \mathrm{Alq}_{3}(40 \mathrm{~nm}) / \mathrm{LiF}(1 \mathrm{~nm}) / \mathrm{Al}(100 \mathrm{~nm})$. The size of substrate was $50 * 50 * 5 \mathrm{~mm}$, and the substrate cutting angle was $45^{\circ}$ and the microlens array was fabricated on the substrate with the method shown in Figure 5(b). The luminance-voltage characteristics and typical external quantum efficiency (EQE) of those organic devices are shown in Figure 7. Simple method about calculating EQE has been reported with some device characteristics including emission spectra, current density, and luminance parameters [31-33]. The luminance of the organic device using substrate with body modification is higher than the other three devices, and the device with normal substrates shows the lowest luminance at the same driving voltage. The highest EQE of device with body modification is $4.67 \%$ and the EQE value is about 1.8 times higher than the device with normal substrate, which means that a light extraction improvement of $80 \%$ 


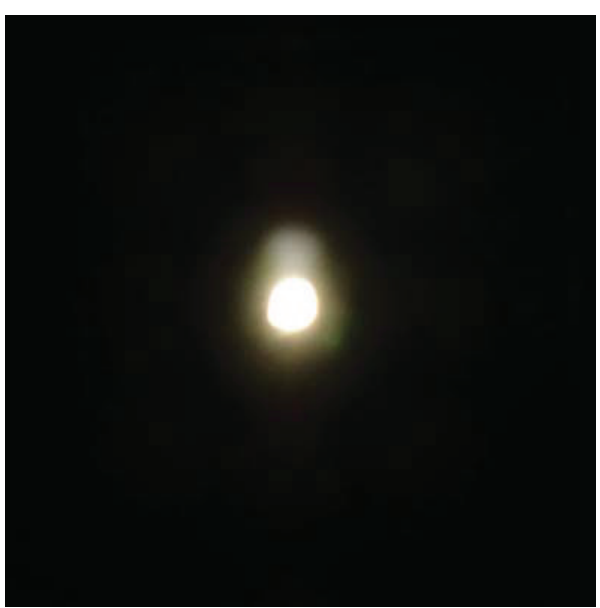

(a)

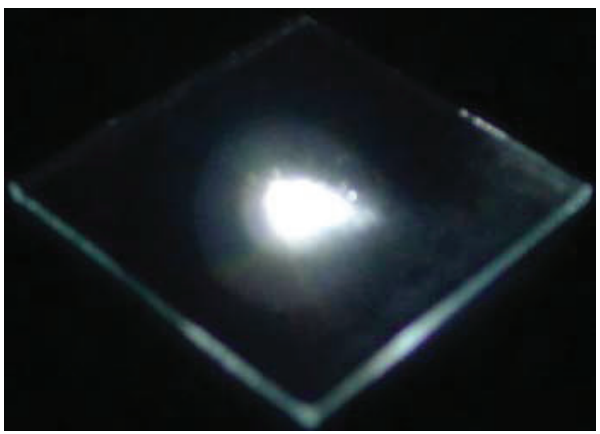

(c)

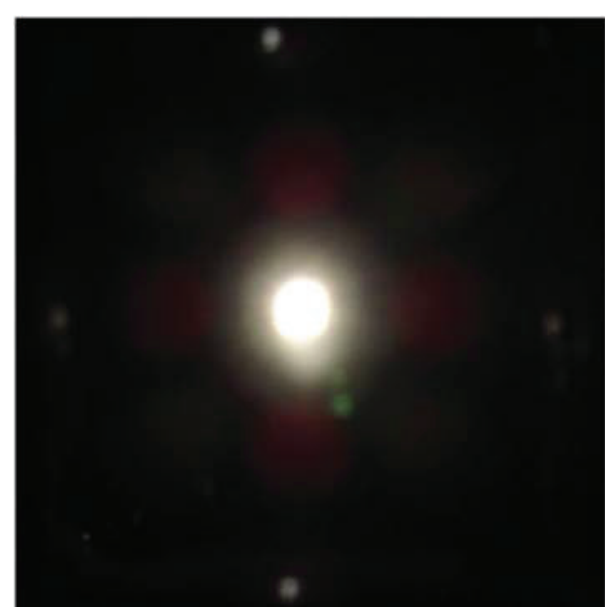

(b)

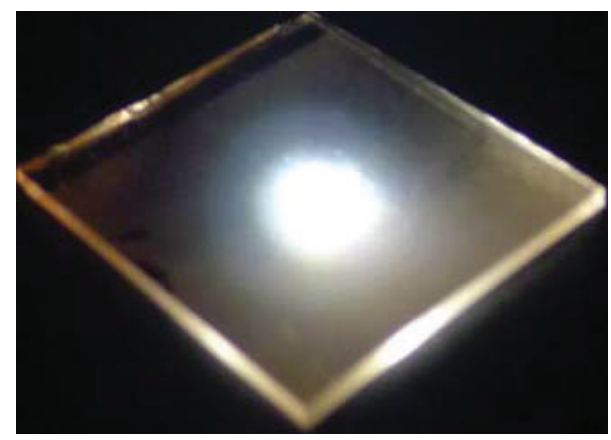

(d)

FIGURE 6: Images of LED dot source through glass substrate: the top two images for comparing the substrate with (b) or without (a) LMRF structure and the bottom two images for comparing the substrate with (d) or without (c) MLA structure.

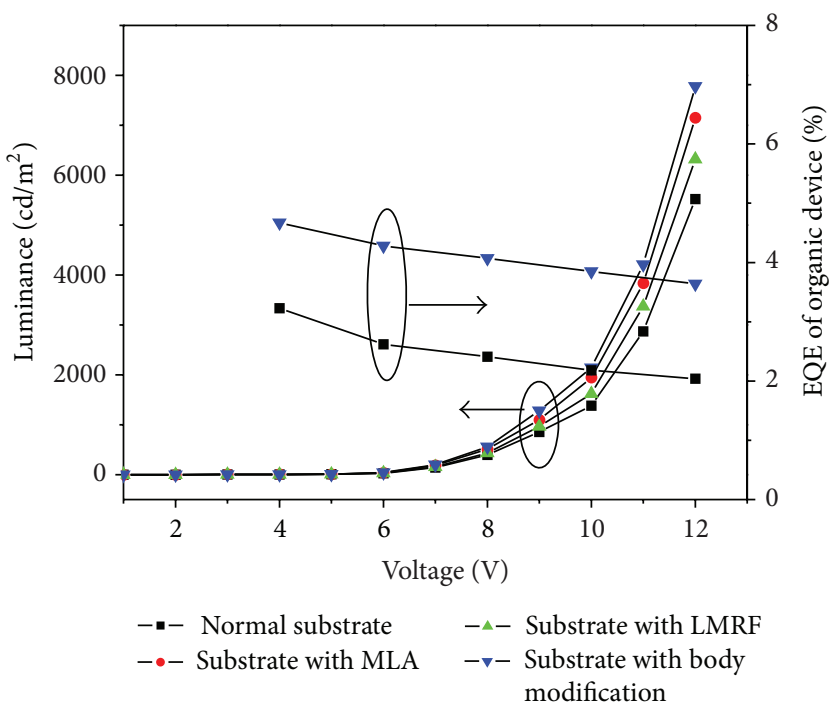

FIGURE 7: Luminance-voltage characteristics and typical external quantum efficiency of four organic devices.

is obtained with the body modification substrate from the experiment results.

\section{Conclusions}

In summary, a facile method of body modification on substrate is introduced to enhance light extraction for organic devices using LMRF coated on the side of substrate and MLA covering the forward surface of substrate. Three-dimensional models of organic devices with different substrate side cutting angle and different contact angle of microlens/substrate were simulated to get the optimized design of substrate structure. According the simulation results, light output ratio of organic device using the substrate with body modification structure 
is 2.15 times higher than the organic device with normal glass substrate, and the light output intensity is more uniform. The LMRF layer is evaporated on the oblique side of substrate and the MLA structure with semicircle shape is fabricated on the substrate using normal photolithography process. The EQE value of fabricated organic device with body modification is about 1.8 times higher than the device with normal substrate from the test results. This method could be widely used to improve the light output efficiency for OLEDs, especially the SSL application.

\section{Conflict of Interests}

The authors declare that there is no conflict of interests regarding the publication of this paper.

\section{Acknowledgments}

This work is supported by National Science Foundation of China (NSFC) via Grant no. 61006036, "the Fundamental Research Funds for the Central Universities" (ZYGX2011X012), and Program for New Century Excellent Talents in University (NCET-10-0299).

\section{References}

[1] H. Uoyama, K. Goushi, K. Shizu, H. Nomura, and C. Adachi, "Highly efficient organic light-emitting diodes from delayed fluorescence," Nature, vol. 492, pp. 234-238, 2012.

[2] Y. Zhang, M. Abdelmalek, Q. Wang, and H. Aziz, "Degradation mechanism in simplified phosphorescent organic lightemitting devices utilizing one material for hole transport and emitter host," Applied Physics Letters, vol. 103, no. 6, Article ID 063307, 2013.

[3] W. H. Koo, S. M. Jeong, F. Araoka et al., "Light extraction from organic light-emitting diodes enhanced by spontaneously formed buckles," Nature Photonics, vol. 4, no. 4, pp. 222-226, 2010.

[4] C. Adachi, M. A. Baldo, M. E. Thompson, and S. R. Forrest, "Nearly 100\% internal phosphorescence efficiency in an organic light emitting device," Journal of Applied Physics, vol. 90, no. 10, pp. 5048-5051, 2001.

[5] J. H. Seo, S. J. Lee, B. M. Seo et al., "White organic light-emitting diodes showing nearly $100 \%$ internal quantum efficiency," Organic Electronics, vol. 11, no. 11, pp. 1759-1766, 2010.

[6] K. T. Kamtekar, A. P. Monkman, and M. R. Bryce, "Recent advances in white organic light-emitting materials and devices (WOLEDS)," Advanced Materials, vol. 22, no. 5, pp. 572-582, 2010.

[7] C. Groves, "Organic light-emitting diodes: bright design," Nature Materials, vol. 12, pp. 597-598, 2013.

[8] A. Chutinan, K. Ishihara, T. Asano, M. Fujita, and S. Noda, "Theoretical analysis on light-extraction efficiency of organic light-emitting diodes using FDTD and mode-expansion methods," Organic Electronics, vol. 6, no. 1, pp. 3-9, 2005.

[9] R. Capelli, S. Toffanin, G. Generali, H. Usta, A. Facchetti, and M. Muccini, "Organic light-emitting transistors with an efficiency that outperforms the equivalent light-emitting diodes," Nature Materials, vol. 9, no. 6, pp. 496-503, 2010.
[10] Y. Sun and S. R. Forrest, "Enhanced light out-coupling of organic light-emitting devices using embedded low-index grids," Nature Photonics, vol. 2, no. 8, pp. 483-487, 2008.

[11] T.-W. Koh, J.-M. Choi, S. Lee, and S. Yoo, "Optical outcoupling enhancement in organic light-emitting diodes: highly conductive polymer as a low-index layer on microstructured ITO electrodes," Advanced Materials, vol. 22, no. 16, pp. 1849-1853, 2010.

[12] Y.-G. Bi, J. Feng, Y.-F. Li et al., "Enhanced efficiency of organic light-emitting devices with metallic electrodes by integrating periodically corrugated structure," Applied Physics Letters, vol. 100, no. 5, Article ID 053304, 2012.

[13] S.-H. Cho, Y.-W. Song, J.-G. Lee et al., "Weak-microcavity organic light-emitting diodes with improved light out-coupling," Optics Express, vol. 16, no. 17, pp. 12632-12639, 2008.

[14] W. H. Koo, S. M. Jeong, F. Araoka et al., "Light extraction from organic light-emitting diodes enhanced by spontaneously formed buckles," Nature Photonics, vol. 4, no. 4, pp. 222-226, 2010.

[15] W. Xu and Y. Li, "The effect of anisotropy on light extraction of organic light-emitting diodes with photonic crystal structure," Journal of Nanomaterials, vol. 2013, Article ID 969120, 6 pages, 2013.

[16] K. Saxena, D. S. Mehta, V. K. Rai, R. Srivastava, G. Chauhan, and M. N. Kamalasanan, "Implementation of anti-reflection coating to enhance light out-coupling in organic light-emitting devices," Journal of Luminescence, vol. 128, no. 3, pp. 525-530, 2008.

[17] T. Bocksrocker, J. Hoffmann, C. Eschenbaum et al., "Microspherically textured organic light emitting diodes: a simple way towards highly increased light extraction," Organic Electronics, vol. 14, pp. 396-401, 2013.

[18] W.-K. Huang, W.-S. Wang, H.-C. Kan, and F.-C. Chen, "Enhanced light out-coupling efficiency of OLEDs with selforganized microlens arrays," in Proceedings of the 44th International Symposium, Seminar, and Exhibition (SID '06), pp. 961963, June 2006.

[19] H. J. Peng, Y. L. Ho, C. F. Qiu, M. Wong, and H. S. Kwok, “Coupling efficiency enhancement of organic light emitting devices with refractive microlens array on high index glass substrate," in Proceedings of the SID 04 Digest, pp. 158-161, 2004.

[20] F. Galeotti, W. Mróz, G. uido Scavia, and C. Botta, "Microlens arrays for light extraction enhancement in organic lightemitting diodes: a facile approach," Organic Electronics, vol. 14, pp. 212-218, 2013.

[21] J. Lim, S. S. Oh, D. Y. Kim et al., "Enhanced out-coupling factor of microcavity organic light-emitting devices with irregular microlens array," Optics Express, vol. 14, no. 14, pp. 6564-6571, 2006.

[22] S. W. Liu, J. X. Wang, Y. Divayana et al., "An efficient nonLambertian organic light-emitting diode using imprinted submicron-size zinc oxide pillar arrays," Applied Physics Letters, vol. 102, Article ID 053305, 2013.

[23] J. Choi, T. W. Koh, S. Lee, and S. Yoo, "Enhanced light extraction in organic light-emitting devices: Using conductive low-index layers and micropatterned indium tin oxide electrodes with optimal taper angle," Applied Physics Letters, vol. 100, Article ID 233303, 2012.

[24] S. Mladenovski, K. Neyts, D. Pavicic, A. Werner, and C. Othe, "Exceptionally efficient organic light emitting devices using high refractive index substrates," Optics Express, vol. 17, no. 9, pp. 7562-7570, 2009. 
[25] Q. Yue, W. Li, F. Kong, and K. Li, "Enhancing the out-coupling efficiency of organic light-emitting diodes using twodimensional periodic nanostructures," Advances in Materials Science and Engineering, vol. 2012, Article ID 985762, 9 pages, 2012.

[26] C. Adachi, M. A. Baldo, S. R. Forrest, and M. E. Thompson, "High-efficiency organic electrophosphorescent devices with tris(2-phenylpyridine)iridium doped into electron-transporting materials," Applied Physics Letters, vol. 77, no. 6, pp. 904906, 2000.

[27] S. R. Forrest, "The road to high efficiency organic light emitting devices," Organic Electronics, vol. 4, no. 2-3, pp. 45-48, 2003.

[28] M.-K. Wei, I.-L. Su, Y.-J. Chen, M. Chang, H.-Y. Lin, and T.$\mathrm{C}$. $\mathrm{Wu}$, "The influence of a microlens array on planar organic light-emitting devices," Journal of Micromechanics and Microengineering, vol. 16, no. 2, pp. 368-374, 2006.

[29] H.-C. Wei and G.-D. J. Su, "Fabrication of a transparent and selfassembled microlens array using hydrophilic effect and electric field pulling," Journal of Micromechanics and Microengineering, vol. 22, no. 2, Article ID 025007, 2012.

[30] S. Lee, E. Wrzesniewski, W. Cao, J. Xue, and E. P. Douglas, "Printed microlens arrays for enhancing light extraction from organic light-emitting devices," Journal of Display Technology, vol. 9, pp. 497-503, 2013.

[31] M. Furno, T. C. Rosenow, M. C. Gather et al., "Analysis of the external and internal quantum efficiency of multi-emitter, white organic light emitting diodes," Applied Physics Letters, vol. 101, Article ID 143304, 2012.

[32] J. Wang and W. Li, "Adjusting white OLEDs with yellow light emission phosphor dye and ultrathin NPB layer structure," International Journal of Photoenergy, vol. 2013, Article ID 639843, 6 pages, 2013.

[33] M. Furno, R. Meerheim, S. Hofmann, B. Lüssem, and K. Leo, "Efficiency and rate of spontaneous emission in organic electroluminescent devices," Physical Review B, vol. 85, no. 11, Article ID 115205, 2012. 

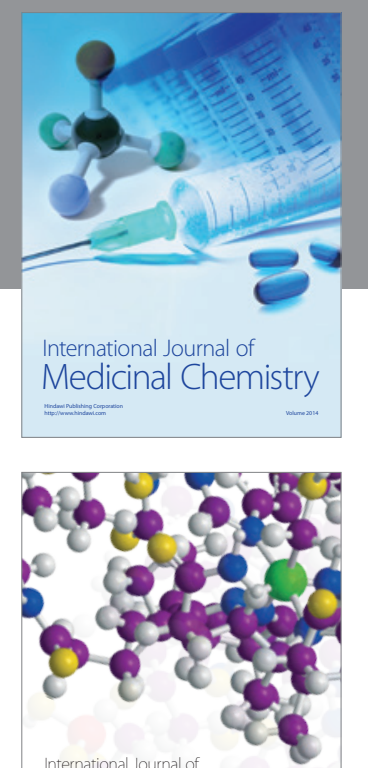

\section{Carbohydrate} Chemistry

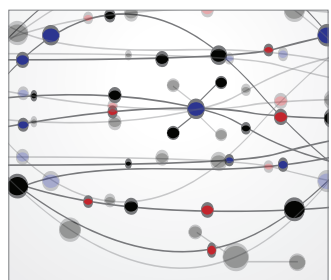

The Scientific World Journal
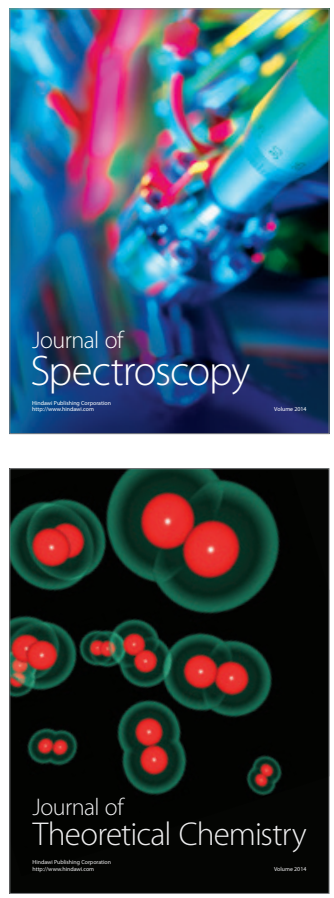
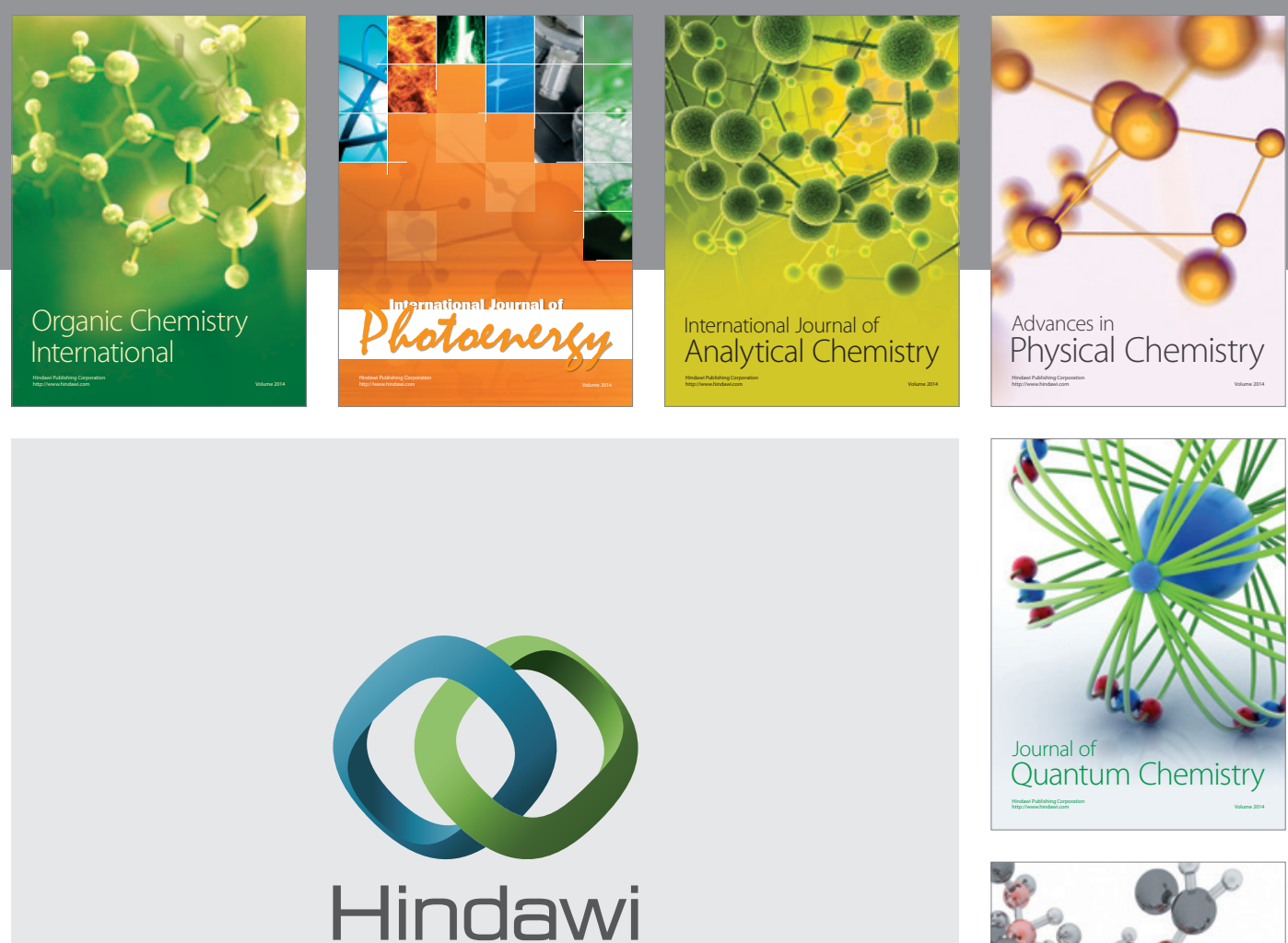

Submit your manuscripts at

http://www.hindawi.com

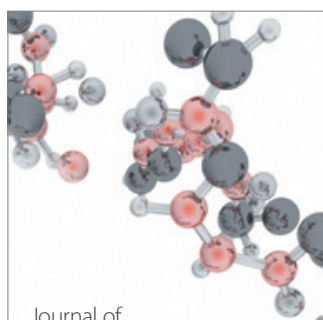

Analytical Methods

in Chemistry

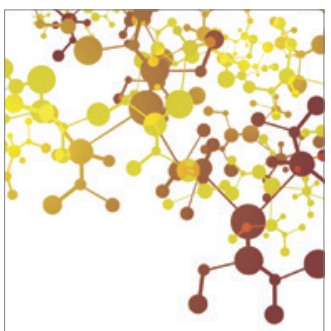

Journal of

Applied Chemistry

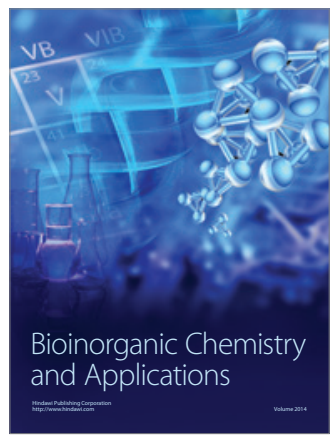

Inorganic Chemistry
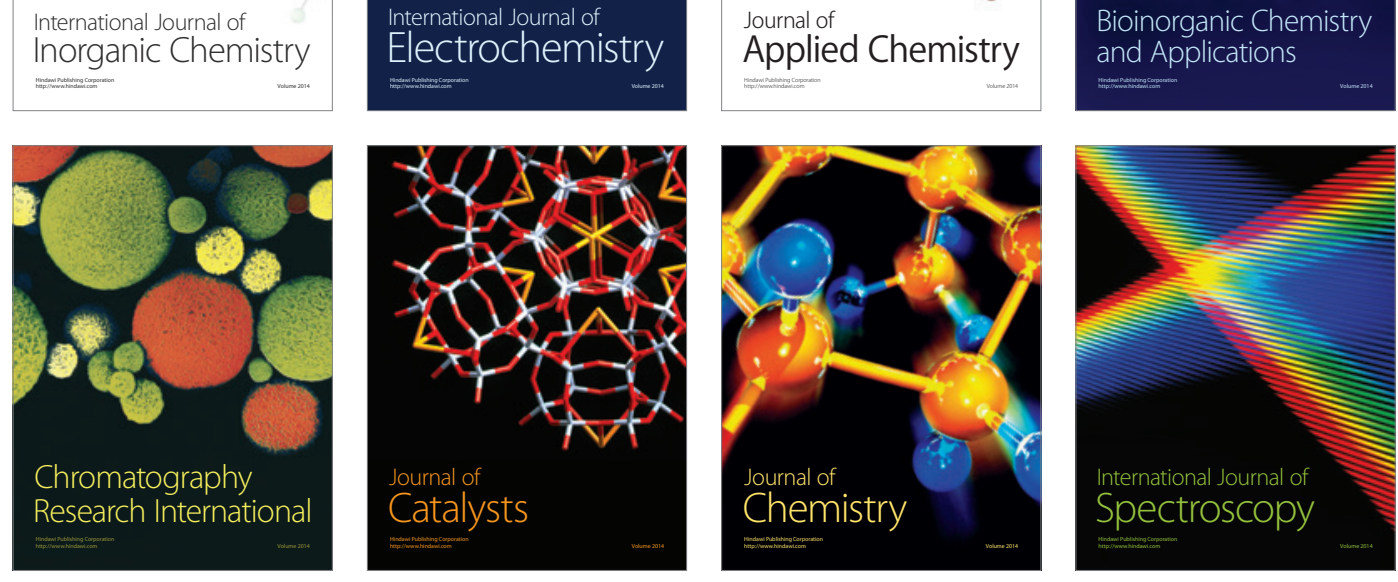